DOI 10.37882/2223-2982.2021.05-2.19

\title{
МОДЕЛЬ ЗАДАНИЙ, ОРИЕНТИРОВАННЫХ НА СОВЕРШЕНСТВОВАНИЕ ЛИНГВОСТРАНОВЕДЧЕСКОЙ КОМПЕТЕНЦИИ У СТУДЕНТОВ-БАКАЛАВРОВ В УСЛОВИЯХ ДИСТАНЦИОННОГО ОБУЧЕНИЯ
}

\section{TASK MODEL OF ENHANCEMENT OF LINGUO-CROSS-CULTURAL COMPETENCE OF BACHELORS OF TECHNICAL STUDIES IN THE CONTEXT OF DISTANCE LEARNING \\ A. Markus \\ G. Raspaeva}

Summary: The aim of the article is to research the task model of linguocross-cultural competence enhancement of bachelors of technical studies under Distance learning condition. In the article the local ascertaining experiment is described, which consists of questionnaire methods, teaching observation, content-analysis method, statistical method DID. In the experiment there were two groups of some students: experimental and control ones. The scientific novelty of the research lies in the development of task model to enhance linguo-cross-cultural competence of bachelors during distance learning. The analysis of the integrated task model which comprises the developed exercise system based on some chosen tools of distant technologies was conducted.

Keywords: linguo-cross-cultural competence, bachelors, distance learning, technical studies.
Маркусь Анна Михайловна

К.филол.н., дочент, Южно-Уральский государственный университет (национальный исследовательский университет), Челябинск markusam@susu.ru

Распаева Гульжан Джамбуловна К.филол.н., дочент, Южно-Уральский государственный университет (национальный исследовательский университет), Челябинск raspaevagd@susu.ru

Аннотация: Целью статьи является выстраивание модели заданий, направленных на совершенствование лингвострановедческой компетенции у бакалавров технических специальностей в условиях дистанционного обучения. В статье описан локальный констатирующий эксперимент, состоящий из опросных методов, педагогического наблюдения, метода контент-анализа и статистического метода DID, в ходе, которого участвовали студенты из экспериментальной и контрольной группы. Научная новизна исследования заключается в формировании модели заданий, ориентированных на совершенствование лингвострановедческой компетенции у студентов-бакалавров в период дистанционного обучения. В результате исследования был проведен анализ интегрированной модели заданий, включающей в себя разработанную систему упражнений, основанных на выбранных инструментах дистанционных технологий.

Ключевые слова: лингвострановедческая компетенция, бакалавры, дистанционное обучение, технические специальности.

педагогических методов с применением актуальных информационных технологий, совмещение получения образования и практического опыта, влияющего на стаж работы по выбранной специальности, посредством чего обучающийся приобретает профессиональные компетенции и знания без отрыва от производства. Инновационным при дистанционном обучении является наличие студенческой мобильности: студенты способны получить образование одновременно в нескольких вузах.

Современные реалии частично видоизменили и методику преподавания иностранных языков, существенно увеличив количество часов на самостоятельную работу студентов, погрузив их в мир интерактивных заданий и тестов. При этом на практике аккумулировалась деятельность, нацеленная на процесс совершенствования лингвострановедческой компетенции, способствующей развитию коммуникации с представителями различных культур в многообразных областях деятельности с уче- 
том толерантного отношения и осознанного принятия специфических традиций разных народов, поскольку с февраля по апрель студенты 1 курса обучения технических специальностей проходят такие объемные модули как «The world of English», «deutschsprachige Länder», «Erfinder und Erfindungen», открывая для себя культурноспецифические особенности менталитета другой страны, установок и ценностей представителей инокультуры.

Целью статьи является выстраивание модели заданий, направленных на совершенствование лингвострановедческой компетенции у бакалавров технических специальностей в условиях дистанционного обучения.

Задачи исследования:

1. выбрать необходимые инструменты дистанционных технологий, направленные на совершенствование лингвострановедческой компетенции в период дистанционного обучения,

2. составить модель заданий, учитывающие дистанционный формат,

3. внедрить эту модель в практику подготовки студентов-бакалавров технических специальностей.

Теоретической базой исследования являлись теории страноведения и лингвострановедения (Е.М. Верещагин, В.Г. Костомаров, Ю.А. Ендольцев, М.Д. Зиновьева, Ю.Е. Прохоров, С.Г. Тер-Минасова, Г.Д. Томахин и др.), концепция межкультурной коммуникации (В.В. Сафонова, С.Г. ТерМинасова, И.И. Халеева и др.), теории совершенствования профессиональных качеств студентов в системе высшего педагогического образования (Н.В. Кузьмина, А.И. Щербаков и др.).

По словам Ж.В. Демьяновой, лингвострановедческая подготовка направлена на решение комплексных задач: от изучения национальных стереотипов поведения и специфики мышления до ценностных ориентаций, актуализирующих необходимость формирования и совершенствования лингвострановедческой компетенции у студентов неязыковых специальностей [7, с. 3].

О.С. Акимова и Ж.В. Демьянова определяют лингвострановедческую компетенцию как «систему лингвострановедческих знаний, умений и мотивов, позволяющая студентам неязыковых факультетов выстраивать свою деятельность на основе лингвострановедческого кругозора и осуществлять полноценную коммуникацию в ситуациях межкультурного общения» [7, с. 10].

Структура лингвострановедческой компетенции трехчастна, включает в себя познавательный, праксиологический и мотивационный компоненты. Познавательный компонент содержит лингвистические и тематические знания, базирующиеся на лингвострановедческом материале. Праксиологический компонент отражает умения в использовании лингвострановедческих знаний. Мотивационный компонент характеризуется мотивами и интересами студентов к изучению иностранного языка [7, с. 11].

Следует подчеркнуть, что в процессе преподавания иностранных языков студентам бакалавриата познавательный компонент аккумулируется путем использования аудио и видео материала с различной тематической направленностью о странах изучаемого языка. Навыки и умения праксиологической составляющей совершенствуются в выполнении студентами проектных работ (2 за семестр). В ходе учебы студенты повышают мотивационный потенциал в осознании своих коммуникационных умений в общении с иностранными студентами, познании традиций и особенностей быта и жизни народа изучаемого языка.

В основе лингвострановедческой компетенции, по мнению Г.Д. Томахина, лежат фоновые знания среднестатистического представителя британской лингвокультурной общности, обладание которыми является условием для адекватной коммуникации между представителями разных культурных сообществ. Студентам необходимо овладеть конкретным набором знаний, находящиеся в канве фоновых знаний иного сообщества, «как невербального компонента коммуникации, как сумму условий, предпосылаемых собственно речевому высказыванию и являющихся национально-специфическим индикатором интракультурного общения» [17, с. 113].

В процессе совершенствования лингвострановедческой компетенции студенты-бакалавры культивируют, как «историко-культурный фон, включающий сведения о культуре общества в процессе его исторического развития, социокультурный фон, этнокультурный фон, включающий информацию о быте, традициях, праздниках, так и семиотический фон, содержащий информацию о символике, обозначениях, особенностях иноязычного окружения» [18, с. 17]. Мы придерживаемся мнения В.П. Фурмановой.

Несмотря на многочисленные работы в исследовательском поле, посвященные изучению лингвострановедческой компетенции, в условиях дистанционного обучения целесообразно обратиться к детальному рассмотрению совершенствования лингвострановедческой компетенции в изменившихся реалиях, выявить специфику содержательных и организационно-педагогических средств в целях совершенствования лингвострановедческой компетенции в режиме дистанционного обучения.

\section{Материалы и методы}

Усиление глобализации и интеграционных процес- 
сов разных стран приводит к развитию международных контактов, при обучении иностранному языку необходимо совершенствовать лингвострановедческую компетенцию посредством специально разработанных заданий, ориентированных на преодоление культурных, этнических стереотипов, способных представить информацию по социальным нормам в процессе межкультурного общения.

Фундаментом проведенного исследования служат как теоретические и практические наработки, систематизированные в сфере российской и зарубежной лингводидактики, так и гуманно ориентированная системно-синергетическая методология, предложенная Г.Н. Сериковым, раскрывающая реализацию процесса индивидуализации в образовательном процессе при дистанционном обучении [15].

При анализе результатов освоения и совершенствования лингвострановедческой компетенции на уровне бакалавриата у студентов технического профиля в связи с изменением традиционного формата был осуществлен локальный констатирующий эксперимент (февраль 2020 - январь 2021) в группах 1 курса технических специальностей (150 студентов разного уровня владения иностранным языком), вбирающий в себя широкий спектр индивидуальных методов: от опросных методов (опосредованное анкетирование, формализованная и неформализованная беседа, интервью, Google-тестирование) до планомерного систематического педагогического наблюдения, а также были использованы метод контент-анализа и статистический метод DID (Difference in differences). Для метода DID были выбраны экспериментальная и контрольная группы и два временных периода: апрель 2020 г. и ноябрь 2020 г.

\section{Результаты исследования}

В проводимых нами опросах приняло участие 150 студентов 1 курса бакалавриата технических специальностей Южно-Уральского государственного университета, респонденты с разным уровнем владения иностранным языком (A1 - В1, изучающих английский и немецкий языки. В анкетировании было задействовано 20 вопросов относительно изменений в методике преподавания иностранного языка при переходе на дистанционное обучение и актуализации при совершенствовании лингвострановедческой компетенции (например, как Вы относитесь к дистанционному обучению, какие положительные аспекты Вы бы хотели отметить, могут ли дистанционные задания заменить традиционные и т.д.).

При подготовке комплекса заданий нами была учтена модель освоения чужой культуры М. Беннета [20, с. 10], представляющая собой основание для понимания многогранности и особенности наших представлений. Согласно данной модели, существует три этнорелятивных ориентации, при которых культура людей воспринимается в контексте других культур (принятие, адаптация, интеграция).

Предложенная нами модель, содержащая комплекс заданий, ориентирована на два составляющих компонента: 1 - интегрирование на первом этапе эксперимента (time 1) специально разработанных упражнений начального уровня, учитывающих процесс принятия. Согласно учебному плану студентам необходимо освоить следующие тематические рубрики: «Out and about», «Shopping», «A wide world», «Fabulous food» и т.д. (для уровня владения языком A1), «Going away», «At home», «Things happen», «Communication», «Appearances», «Looking ahead» (A2) (английское отделение), «deutschsprachige Länder», «Hochschulausbildung», «Erfinder und Erfindungen», «Umweltschutz» (немецкое отделение).

В экспериментальной группе при переходе на дистанционное обучение в период COVID 19 для совершенствования лингвострановедческой компетенции на первом этапе использовались следующие ориентиры: Google Meet с его встроенной онлайн-доской Jamboard (виртуальная доска позволяет раскрыть потенциал групповой работы, визуализируя результат), Mentimeter, Quizziz, flipped classroom и т.д.

Задания были выстроены при непосредственном активном использовании всех перечисленных возможностей, способствующих совершенствованию лингвострановедческой компетенции бакалавров.

Примеры заданий:

1. подготовительные, тренировочные упражнения, вводящие терминологию, соотносимую с тематикой, использование Jamboard и Mentimeter.

- Подбор российских реалий для английских/немецких реалий,

- заполнение пропусков лексическими единицами с лингвострановедческим компонентом,

- составление диалога по указанной тематике с применением английских/немецких реалий,

- «погружение в среду» посредством flipped classroom: прохождение онлайн-заданий ВBC. Com / Deutsche Welle, связанных со спецификой указанных тем, просмотровое чтение, ориентированное на ознакомление с иноязычными реалиями, закрепление на основе видео-репортажей с последующим представлением вопросов в Quizziz.

2. Речевые упражнения с редуцированной опорой (по карточкам)

3. Проведение экскурсий в Google expeditions (групповые и индивидуальные туры) по английскому языку. Онлайн-сервис позволяет включать собственные фотоколлажи с информативным рядом. 
Второй этап эксперимента - задействование на втором этапе эксперимента (time 2) заданий, учитывающих процесс адаптации и интеграции. Тематический ряд разнопланован: «All about you», «In class», «Favorite people», «Everyday life», «Free time», «Neighborhoods» (A1), «Making friends», «Interests», «Health», «Celebrations», «Growing up», «Around town» (для уровня владения языком A2), «» (А2) (английское отделение), «berühmte Familien», «modern Lebensweise der Menschen in den EU-Ländern», «Sprachenlernen» (немецкое отделение).

Примеры заданий:

- представление докладов на странице Wikis в Moodle, посвященных известным личностям в Америке, Германии, России,

- составление Интернет-страницы посредством tilda.cc, раскрывающую студенческий потенциал по тематике «Everyday life», «Free time», «Neighborhoods» (A1), «Celebrations», «Around town», «berühmte Familien», «modern Lebensweise der Menschen in den EU-Ländern» с последующим тестированием на основе Quizziz (назначение домашнего задания, асинхронный способ).

- создание креативных презентаций и анимированных видео на тематику «All about you», «Making friends», «Interests», «Sprachenlernen» в групповом формате в малых группах (3-4 студента) посредством графического редактора Canva, PowToon.

В контрольной группе студенты выполняли 2 проектные работы в семестре, в зависимости от состояния серверов презентации были представлены в программе Power Point в ВВВ или Google Meet.
Анализ данных, полученных при формализованной и неформализованной беседах и Google-тестировании, отражает заинтересованность студентов в изучении данных тем (91\%), выявлены наиболее «близкие» рубрики, представленные в диаграмме 1.

Локальный констатирующий эксперимент был осуществлен в течение года (февраль 2020 г. по январь 2021 г.). На начальном этапе были выделены две группы (экспериментальная и контрольная) и два временных периода (time 1 - апрель 2020 г. и time 2 - октябрь 2020 г.), задействованных при методологии DID.

В апреле 2020 г. студенты 1 курса бакалавриата технических специальностей выполняли проверочные задания, анализирующие результат освоения и совершенствования лингвострановедческой компетенции. Комплексное тестирование состояло из 60 вопросов, 10 из которых представляли собой аудиозаписи и 3 видеозаписи. Задания проверялись автоматически электронной образовательной средой Moodle и были разработаны для каждого уровня владения языком, с усложнением лексико-грамматических аспектов. В начале октября 2020 г. были проведены итоговые мероприятия по выявлению результатов освоения лингвострановедческой компетенции и ее совершенствования. Структура заданий осталась неизменной.

Результаты проведенного анализа представлены в диаграмме 2.

Анализ полученных данных позволяет предположить, что применение в экспериментальной группе (P) за-

\section{Значимость компонентов лингвострановедческой компетенции для ббакалавров 1 курса обучения}

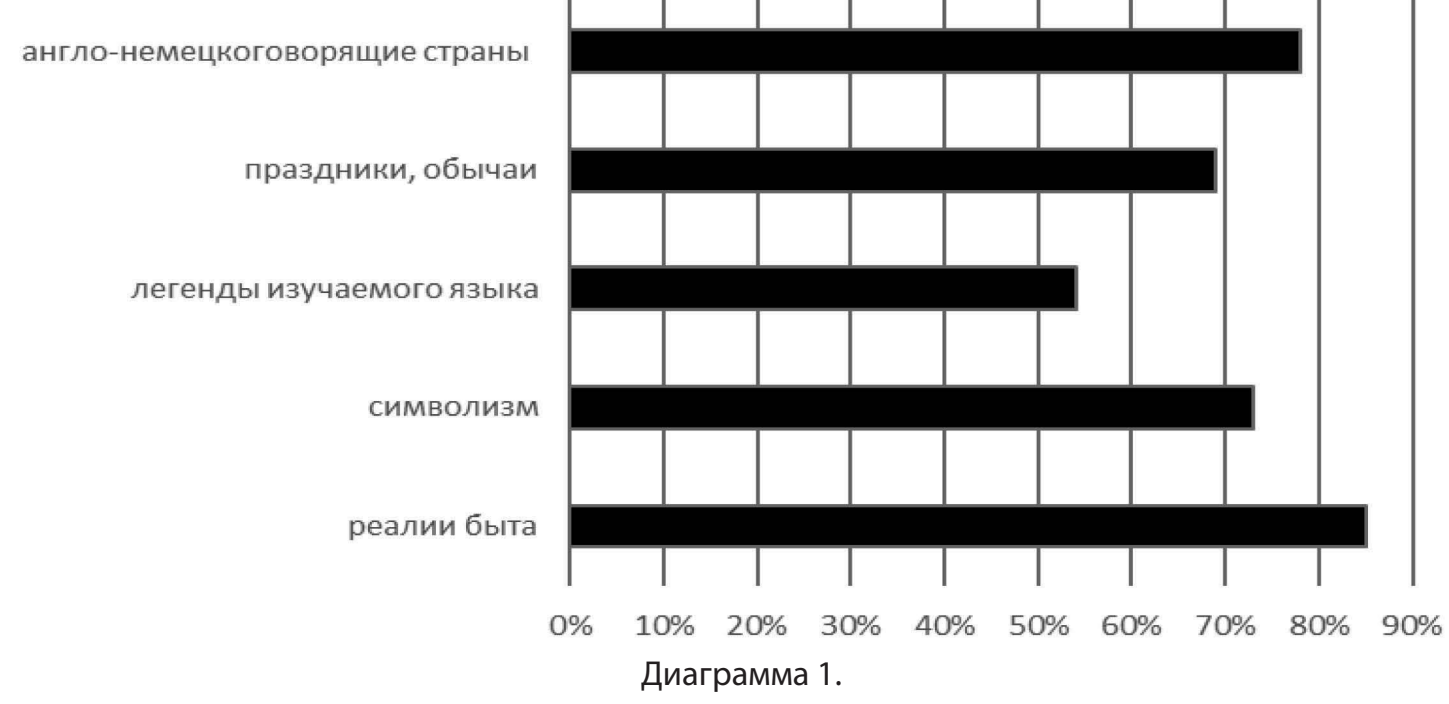


Таблица 1.

\begin{tabular}{|c|c|c|c|}
\hline & Контрольная группа (S) & Экспериментальная группа (Р) & Разница \\
\hline & \multicolumn{2}{|c|}{ Результаты в процентом соотношении } & \\
\hline Апрель 2020 г. $t 1$ & $67 \%$ & $70 \%$ & $-3 \%$ \\
\hline \multirow[t]{2}{*}{ Октябрь 2020 г. t2 } & $73 \%$ & $84 \%$ & $-11 \%$ \\
\hline & $6 \%$ & $14 \%$ & $-8 \%$ \\
\hline
\end{tabular}

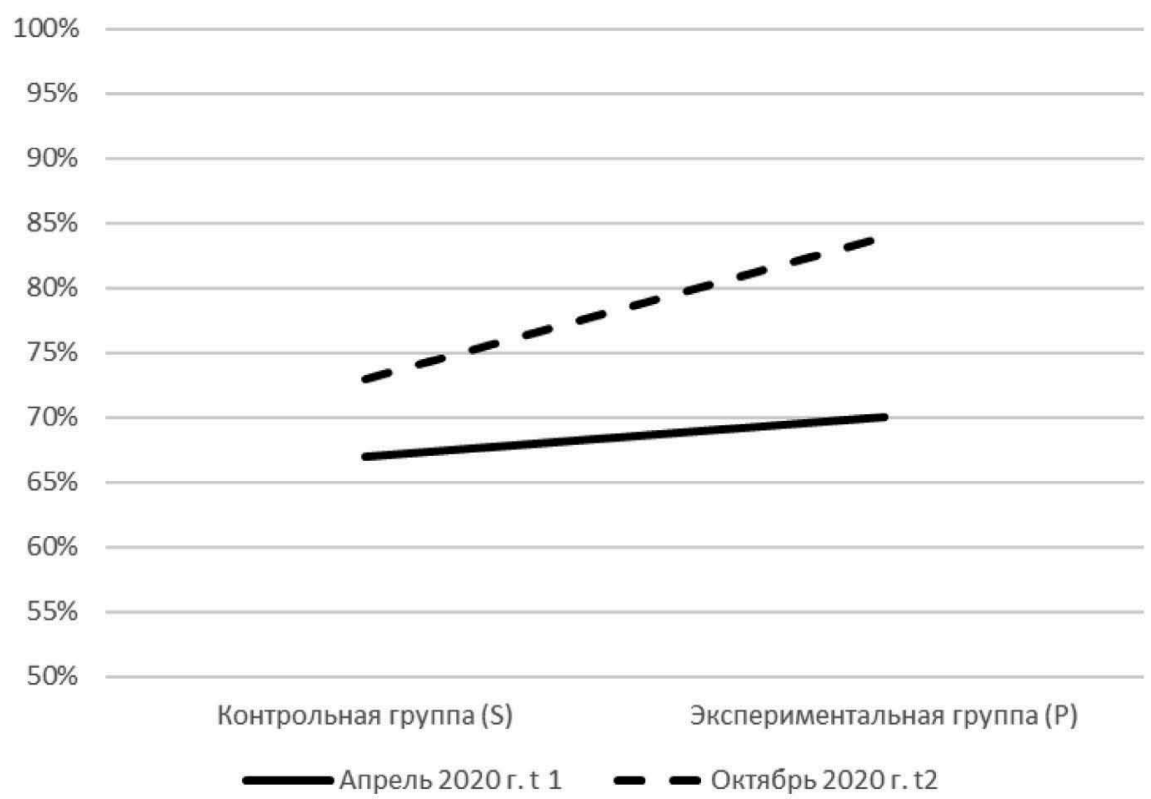

Диаграмма 2.

явленных в статье актуальных методологических инноваций значительно способствовало совершенствованию лингвострановедческой компетенции (11\% на октябрь 2020 г.) по сравнению с контрольной группой. Разность разностей составила 8 \%. Мы планируем расширить сферу применения данных методов, направив их потенциал на совершенствование другого рода компетенций.

\section{Зак^ючение}

Вынужденный переход на дистанционное обучение, обусловленный распространением коронавирусной инфекции, повлиял на существенное изменение в структуре образовательного процесса, способствовал кардинальной перестройке системы подготовки обучающихся на всех этапах обучения.

В статье была предложена модель заданий и проанализированы результаты ее интеграции для совершенствования лингвострановедческой компетенции в условиях дистанционного обучения. Данная модель заданий содержит разнообразные задания, затрагивающие весь тематический спектр курсов.

Применение инновационных инструментов (Google Meet с его встроенной онлайн-доской Jamboard, стра- ницы Wikis в Moodle, Quizziz, flipped classroom, tilda.cc, Canva, Mentimeter, Powtoon) расширили возможности совершенствования лингвострановедческой компетенции, значимой для выстраивания полноценного межкультурного взаимодействия. В рамках совершенствования данной компетенции у бакалавров технических специальностей первого курса обучения формируются представления о реалиях стран изучаемого языка, их традициях и обычаях, раскрывается палитра со страноведческой и культуроведческой информацией, служащей одной из основ иноязычного общения.

Анализ использования выбранных инструментов подтверждает необходимость их внедрения при дистанционном обучении. Однако, учитывая неуклонную тенденцию к возобновлению очного формата в обучении, возможно рассмотреть применение актуального инструментального поля в традиционном формате.

Перспективные направления исследования заключаются в применении и в анализе эффективности данной модели заданий со студентами гуманитарного профиля. Планируется расширение библиотеки экскурсионных туров в сервисе Google Expeditions для студентов, изучающих немецкий язык, целесообразно внедрить экскурсии с сюжетами о немецких городах с вопросами, ориентированными на разный уровень владения языком. 


\section{ЛИТЕРАТУРА}

1. Акимова 0.С. Формирование лингвострановедческой компетенции старших школьников // Молодой ученый. 2016. № 8. С. 896-898.

2. Васильева Г.М. Лингвокультурологические аспекты русской неологии: автореферат дис. . . док.филол. наук. Санкт-Петербург, 2001. 38 с.

3. Верещагин Е.М. Лингвострановедческая теория слова. М.: Рус. яз., 2000. 320 с.

4. Верещагин, Е.М. Язык и культура: Лингвострановедение в преподавании русского языка как иностранного. М.: Индрик, 2005. 1040 с.

5. Воробьев, В.В. Лингвокультурология. Москва: Российский ун-т дружбы народов, 2008. 336 с.

6. Гудков, Д.Б. Теория и практика межкультурной коммуникации. М.: Гнозис, 2003. 288 с.

7. Демьянова Ж.Б. Формирование лингвострановедческой компетенции студентов неязыковых факультетов педагогического вуза: автореф. дис. канд. пед. наук. Челябинск, 2010. 24 с.

8. Демьянова, Ж.В. Основные компоненты процесса формирования лингвострановедческой компетенции у студентов неспециального факультета педвуза // Образование и наука (Уральское отделение РАО). 2007. № 7(11). С. 113-119.

9. Емельянова Я.Б. Лингвострановедческая компетенция переводчика: теория и практика. Нижний Новгород, 2010. С. 105-107.

10. Красных В.В. Этнопсихолингвистика и лингвокультурология. Гнозис, 2002. 284 с.

11. Лысакова И.П. Лингвокультурология и межкультурная коммуникация: к вопросу о понятийном аппарате дисциплин // Вестник РудН. Серия: Вопросы образования: языки и специальность. 2008. № 4. С. 50-53.

12. Маслова В.А. Лингвокультурология. Введение: учеб. пособие для бакалавриата и магистратуры / отв. ред. У.М. Бахтикиреева. М.: Издательство Юрайт, 2018. $208 \mathrm{C}$

13. Орусова 0.В. Как коронавирус изменил систему высшего образования: анализ перехода вузов на дистанционное обучение. // Научное обозрение. Серия 1. Экономика и право. 2020. № 3. С. 184-196.

14. Рыкова Е.Б. Формирование страноведческой компетенции иностранных студентов при обучении русскому языку на материале советской эпохи: автореф. дис. канд. пед. наук. Санкт-Петербург, 2012. 24 с.

15. Сериков Г.Н. Основание педагогических исследований. Челябинск: ИИуМЦ «0бразование», 2005. 238 с.

16. Тер-Минасова С.Г. Язык и межкультурная коммуникация: учеб. пособие для студентов, аспирантов и соискателей по специальности «Лингвистика и межкультур. коммуникация». М.: Слово/Slovo, 2000. 261c.

17. Томахин Г.Д. Реалии-американизмы: пособие по страноведению. М.: Высш. шк, 2006.320 с.

18. Фурманова В.П. Межкультурная коммуникация и лингвокультуроведение в теории и практике обучения иностранным языкам. М., 2005. 123 с.

19. Шаклеин В.М. Лингвокультурная ситуация в современной России. Монография. М.: Флинта: Наука, 2010. 147с.

20. Bennett M.J. Basic Concepts of Intercultural Communication: Paradigms, Principles, Practices. Boston: Intercultural Press, 2013.260 p.

21. Hammer M.R. Measuring intercultural sensitivity: The intercultural development intentory // International Journal of Intercultural Relations. 2003. V. 27. pp. 421-443.

22. Sleptsova G.N. Linguistic and cultural approach to teaching a foreign language as a condition for development of cross-cultural competence of bachelors-teachers // Integrating Engineering Education and Humanities for Global Intercultural Perspectives. 2020. V. 131. pp. 222-230. 